Send your letters to the editor, British Dental Journal, 64 Wimpole Street, London W1G 8YS or by email to bdj@bda.org

Priority will be given to letters less than 500 words long. Letters should be typed. Authors must sign the letter, which may be edited for reasons of space

\section{Foreign dentists}

Sir, I read with interest the communication from the Chief Dental Officer Professor Bedi, the arrangements undertaken by the Department of Health to recruit 1,000 foreign dentists by October 2005 to work on in this country. India is the best stalking location apparently following a recruitment trip, with Poland offering a relatively small top up for our West Country requirements. One or two ethical matters spring to my mind here, and perhaps a response from the authorities would be of general interest. Are the countries involved, India and Poland, wholly enthusiastic about releasing their dentists to supply our needs? Is compensation for the training costs of the new graduates being offered, and how much? Do these countries have a large excess of dentists such that they can export them, if so, then perhaps they might consider the cost of the excess training provided. There is also the question of whether standards of ability are assessed on the influx of the new thousand. From my thinking, having graduated at University College Hospital, London which was closed down many years ago along with the Royal Dental Hospital, London, the answer to the problem of dental manpower shortage is to restore our home grown prodigy rather than to embark on a poaching programme.

C. W. Crome

Surrey

\section{Professor Raman Bedi, Chief Dental} Officer for England responds: C W Crome's letter about the overseas recruitment of dentists incorrectly states that the Department of Health is undertaking to recruit 1,000 overseas dentists by October 2005.

While it is certainly our intention to recruit 1,000 whole time equivalent dentists by next October in order to make access easier, this will not be solely via international recruitment. Approximately two thirds of this target is comprised of international and domestic recruits, many returning from a career break. The remaining third is drawn from existing dentists in England increasing their commitment to the NHS. The Department of Health does not recruit in any country unless there is a government to government agreement. All dentists brought in from overseas have to meet stringent criteria with regard to both their clinical skills and their knowledge of English.

This level of international recruitment is an interim measure whilst we expand dental education in this country. This will begin this autumn with 170 additional dental undergraduate places being made available from October 2005, representing a 25 per cent increase in dental training places. This - plus new investment of $£ 80$ million capital over the next four years means there will be some 850 additional dental students in training by 2010/11. But, because training takes five years to complete, we need an immediate solution in place as well - hence the international recruitment initiative, which is both ethical and effective.

In response to the issue of training costs, non UK trained health professionals have been working in the NHS for some considerable time and it has never been DH policy to pay training costs back to their host country. As indeed we have never attempted to recover our training costs if a UK graduate emigrated.

I would conclude by stressing that improving patients' access to NHS dental care remains a key priority, as demonstrated by progressive increases in investment. As a result, funding for dental services for 2005/06 stands at some 19 per cent higher than for 2003/04. doi: 10.1038/sj.bdj.4812334

\section{Injury assessing}

Sir, I write in response to the feature on BBC Northwest Tonight on the 28/02/05: "Field Hospitals on the weekend in Oldham City centre".

As a Maxillofacial SHO, I am familiar with the trauma associated with excessive alcohol consumption and I appreciate the congestion and workload this causes to A\&tE departments. Whilst the attempt to reduce the considerable strain on A\&tE departments is to be applauded, I was horrified to note that a non-dentally qualified person was assessing dental and facial injuries.

For example, a young gentleman who avulsed a tooth was told to visit his GDP, with no attempt being made to re-implant said tooth. In another example, a

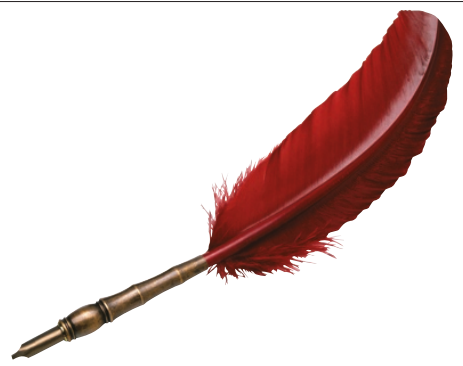

gentleman who had sustained facial lacerations was sutured without recourse to a soft tissue $x$-ray. Both examples highlight non-compliance of guidelines.

Perhaps a MFU SHO should have been on site to treat patients directly or at the very least one made available to contact for suitable advice. I assume an MFU specialist was consulted with regards to the highlighted examples. However, if this is not the case then this issue surely merits further debate.

C. Gardener

By email doi: $10.1038 /$ sj.bdj.4812335

Dental project

Sir, thank you for publishing the article on Dental Project Peru printed in BDJ 2004, 196: 370. I was moved by Jacqui Nimmo's story of the people of the Apurimac region of Peru and inspired by her determination to relieve the dental suffering of the remote and needy village folk.

Her website www.dentalprojectperu.org added to my resolve to visit Peru and these remarkable people. I was not disappointed. Having recently returned from one of the six trips organised by Jacqui since your article, I can honestly say that it was one of the most rewarding and fascinating experiences of my career to date. Sharing the warmth and joyful nature of communities that have so little and being made welcome by rows of apprehensive yet friendly faces was a truly humbling experience. In one village where none of the mud houses were big enough to accommodate us and our portable dental chairs nor light enough for us to work, we opted to work outdoors with the llamas and awesome views across the Andies. This is a vision I have brought back to my surgery and serves to remind me of the diversity of cultures and the privileges that we sometimes take for granted. How different things could be! The ongoing plan to train local health care professionals in basic pain-relieving dentistry will help to make the project more sustainable. For any reader interested in this work or in donating towards it may I urge you to visit the website or the project.

\section{E. Roberts}

Wolverhampton

doi: $10.1038 /$ sj.bdj.4812336 